\title{
Investigation and Analysis of the Current Situation of Olive-Stone Carving Inheritance in Guangzhou
}

\author{
Zhaofeng Hou* \\ Guangzhou Huashang College, Guangzhou 511300, Guangdong Province, China
}

*Corresponding author: Zhaofeng Hou, jingtianxingqi@163.com

\begin{abstract}
The issue of inheriting and developing traditional handicrafts in this contemporary society is being explored by all walks of life in China. Taking the olive-stone carving in Guangzhou as a case, field investigations and analyses of its current situation of inheritance have been conducted. It has been found that although the government in Guangzhou has been paying more attention to olive-stone carving, there are still many problems, including the shortage of raw materials, no inheritors, low market recognition, and inadequate promotion. Therefore, the local government has cooperated with schools and craftsmen to search for key solutions in regard to raw material protection, training of inheritors, product development, and product promotion.
\end{abstract}

Keywords: Olive-stone carving in Guangzhou; Olive stone; Carving; Handicraft; Inheritance

Publication date: December 2021; Online publication: December 31, 2021

\section{Introduction}

As a category of three-dimensional micro-carving, olive-stone carving in Guangzhou is one of the outstanding traditional handicrafts in Lingnan, China, and one of the national intangible cultural heritage projects. A combination of embossment, circular carving, line carving, and openwork carving are usually used to carve on its raw material - black olive stone. The handicraft is characterized by an elegant shape, a small size, and an exquisite form as well as the common contents of auspicious patterns, folk stories, and life scenes, which enrich the cultural, artistic, and historical values ${ }^{[1]}$. Taking olive-stone carving in Guangzhou as the research subject, its current situation of inheritance is explored in this paper through investigations and literature review.

Since the end of 2019, olive-stone carving in Guangzhou has been deemed highly as a research topic. The current situation of its inheritance mainly in Zengcheng, Guangzhou, has been investigated through interviews with Zhou HJ, the inheritor of olive-stone carving in Guangzhou, and Peng XR, the Director of Intangible Cultural Heritage Inheritance Department, Zengcheng Cultural Bureau, Guangzhou, as well as the visits to local schools. In this way, an understanding of its protection and inheritance has been generated from the perspectives of the inheritor, the local government, and schools. In addition, the author also participated in its inheritance work, such as learning the handicraft process and artistic value of olive-stone carving in Guangzhou from the inheritor and promoting the intangible culture through campus activities. Furthermore, the author also participated in the creation of online short videos of olive-stone carving culture in Guangzhou to promote the culture among young people with the help of online platforms, in hope to encourage them to understand and attach importance to this traditional handicraft as well as actively participate in this inheritance work. 


\subsection{Geographical background}

Guangzhou, the capital of Guangdong Province, is the largest city in southern China. It is located in the central and northern of the Pearl River Delta and at the convergent point of three upstream rivers: the East River, the North River, and the West River. It is dominated by a subtropical monsoon climate, warm and rainy, which is conducive to the growth of plants. Guangzhou is an important production area of black olives, which are high-quality materials for olive-stone carving. Among them, the black olive in Zengcheng, known as the "hometown of black olives," is the most famous. There, black olives are cultivated on a large scale with a large yield. Each of it is characterized by a large olive stone, small kernel, thick core wall, smooth texture, high oiliness, deep color, etc. Its hardness is higher than that of ivory and especially suitable for carving. Therefore, the black olives produced in Zengcheng are popular and deeply loved by olive-stone carving artists all over China. In addition, many olive stones used in Suzhou and other regions also come from Zengcheng.

\subsection{Historical origin}

The olive-stone carving handicraft in Guangzhou has a long history and profound culture. According to historical records, it first appeared in Zengcheng, Guangzhou, more than 300 years ago. In the early days, the works of olive-stone carving tended to be natural. In particular, the olive stones were carved into small pieces, such as human clothing accessories and fan pendants for literatus. Temples also distributed boatshaped olive-stone handicrafts, which carry the meaning of "divine intervention," as gifts to pilgrims. During Xuanzong period of the Ming Dynasty, the emperor was fond of olive-stone carving, which triggered an extreme passion among the society. Thereafter, as the aesthetic orientation changed, its conception became more exquisite, and carving technology developed to be more professional. This resulted in the emergence of a large number of olive-stone carving works with varying topics and contents. Olive-stone carving, previously as a "modest carving skill" among the folks, was also officially recognized then. According to Zengcheng County Annals, olive-stone carving in Zengcheng became a royal tribute and was famous all over the country during Xianfeng period of the Qing Dynasty. Benefiting from the favorable environment and the unique producing area, many local superb craftsmen appeared. During the reign of Emperor Qianlong in the Qing dynasty, Chen ZZ, a master of olive-stone carving, created an excellent work, Dongpo's Night Tour on the Red Cliff, on the basis of previous works. Eight figures were carved on a small boat, smaller than a large thumb, and each figure was elaborate and lively. During Xianfeng period of the Qing Dynasty, Zhan JS was even better at creating this handicraft. It has been recorded in The Guangzhou Province Annuals that Zhan JS was good at carving olive stones and that he devoted all his energy to carving. The elaborate masterpiece, Su Dongpo's Night Tour on the Red Cliff Boat, made Zhan JS the "king of carving." In addition to being proficient in carving boats, he was also skillful at carving arhat, Guanyin, rocks, trees, etc. His arhat work was extremely skillful, reflecting an arhat holding a bowl with a dove perching on it and facing inwards. The dove being as small as a fledgling louse was indeed equipped with all its physical parts. With a unique regional culture, olive-stone carving in Guangzhou has been exported over a long period of time. It has been recorded in Lingnan Folk Arts that in the 1930s, olivestone carving in Guangzhou was flourishing because foreign merchants were searching for such works. However, its export was affected during the Anti-Japanese War. After the founding of the People's Republic of China, Guangzhou finally resumed production and set up an olive-stone carving team to export handicrafts, carrying the brand of Chinese Olive-Stone Carving. During this period, such handicrafts were also given to foreign dignitaries as national gifts. Carrying the mission of cultural exchange between China and foreign countries, olive-stone carving in Guangzhou experienced unprecedented, brilliant achievements. However, in the late 1980s, this handicraft was once endangered because of the shortage of raw materials and the impact of the market economy. In recent years, with the support of the government and the appeal 
of people with insight, olive-stone carving in Guangzhou has been revitalized. Old craftsmen continue to devote themselves to the handicraft, and young people are also involved in this process, committing themselves to the inheritance and regeneration of this traditional handicraft.

\section{Problems encountered in the inheritance of olive-stone carving in Guangzhou}

The handicraft of olive-stone carving in Guangzhou that has been passed down from generation to generation carries historical memory, integrates the wisdom of craftsmen, and entrusts the emotions of craftsmen. From its current situation, people have realized its cultural value and artistic charm, but this handicraft still faces some dilemmas of survival in the process of inheritance and development, mainly manifested in four aspects.

\subsection{Shortage of raw materials}

Guangzhou's olive-stone carving is highly dependent on raw materials, so high-quality olive stone is one of the key factors for its success. There are strict criteria for carving olive stones. Specifically, the olive stones should be large, hard, $5 \mathrm{~cm}$ in length, and $2 \mathrm{~cm}$ in diameter, requiring black olive trees to be of high quality. They should be old enough, preferably over a hundred years, and have not been grafted or excessively treated with inorganic fertilizers ${ }^{[2]}$. However, due to the long growth cycle and people's pursuit for economic interests, lands have been over-exploited, and a large number of black olive trees with the capacity of producing large fruits have been cut down, grafted, or over-fertilized, resulting in a decrease in the quantity and quality of olive stones that meet the criteria for carving. Hence, the situation where no olive stones can be carved has surfaced.

\subsection{No inheritors}

Similar to other traditional handicrafts in China, olive-stone carving in Guangzhou has a relatively single way of inheritance; that is, through the teaching practices of fathers and teachers via words and deeds. Due to the complexity of the process, long learning cycle, and low income, many young people either give up or lose the desire for learning, thus choosing to venture in other profitable industries. On the other hand, some young people who are really interested in the handicraft are unable to find a way to learn the skill. Therefore, a situation of "no inheritors" has occurred.

\subsection{Low market recognition}

With a relatively single function, traditional olive-stone carving handicrafts in Guangzhou are mainly used for appreciation and collection. Most of the works are traditional rather than innovative, mainly manifested in three aspects: they have a relatively fixed aesthetic style; they are of high costs due to their complexity and low work efficiency; the market operation is difficult because of the poor awareness of product development. All these result in a small audience group, difficult sales, and low market recognition.

\subsection{Inadequate promotion and popularization}

As a minority intangible cultural heritage, olive-stone carving in Guangzhou does not enjoy a high reputation in China. Although the local cultural and tourism bureaus have tried to expand its popularity by holding various cultural festivals and establishing inheritance bases, which have achieved effects in a small range, its publicity among young audiences is far from desired. In a sample survey conducted in a university in Guangzhou, it has been found that only $56 \%$ of the students have heard of olive-stone carving in Guangzhou, $38 \%$ have observed olive-stone carving works in local museums, and only less than $10 \%$ have 
good knowledge about the olive-stone carving culture.

\section{Countermeasures of the inheritance and development of olive-stone carving in Guangzhou}

\subsection{Raw materials protection}

The local government is supposed to establish a database of old black olive trees covering contents, such as the number, range, age, and planting situation, prior to carrying out protection measures. For example, a black olive-stone base has been set up at Mid-lake Island in Zhengguo Town, Zengcheng to manage the 100 -acre old olive-stone trees at the base. With regional tourism development, the promotion of olive-stone carving culture in Guangzhou should be strengthened to allow villagers to recognize the economic value of olive stones and improve their protection awareness ${ }^{[3]}$, thereby laying a solid foundation for the inheritance of this handicraft. For example, the Twin Dragon Mountain Park in Zengcheng received help from the villagers to protect the old black olive trees. Every October, the Black Olive Cultural Festival is held to exhibit olive-stone carving handicrafts, allowing visitors to experience the charm of this cultural heritage.

\subsection{Cultivating inheritors through multiple channels}

In order to change the situation of "no inheritors" in olive-stone carving in Guangzhou, it is necessary to broaden the channels and change the single method of learning from fathers and teachers. First of all, olivestone carving studios under the name of renowned master should be established, so that people who are really interested in olive-stone carving are given the opportunity to join in the inheritance mission during their spare time. A typical example is the Olive-Stone Craftsman and Olive-Stone Park founded by Zhou $\mathrm{HJ}$, an inheritor of olive-stone carving. Second, olive-stone carving should be introduced into the campus. Many primary and secondary schools in Guangzhou have established relevant cultural inheritance bases on campus, so that students are exposed to olive-stone carving at an early age and are expected to cultivate their interests through interest-oriented classes or training classes. Finally, with the help of online platforms, the craftsmen of olive-stone carving can reach out to the lives of modern people through live broadcast, online performances, and recorded online classes. The internet provides online platforms for these fans from different regions to learn and communicate with each other.

\subsection{The innovative development of olive-stone carving works}

Targeting the problems of a traditional single function, fixed style, small audience group, and low popularity among younger age groups, the inheritor, Zhou HJ, proposed to enrich the category and increase the practicability of olive-stone carving products through the combination of the handicraft with modern aesthetic and innovative forms, including cultural innovative products, tourism commodities, as well as cultural derivatives that are fond and affordable by the younger age groups. "Transaction is the best protection and using is the best inheritance," said Zhao P, the Director of the China Handicraft Development Research Center. The inheritance of olive-stone carving in Guangzhou is embodied in the handicrafts and the culture, not the products themselves. Therefore, the acceptance of olive-stone carving products by the market does not only benefit the craftsmen, but also contribute to the inheritance of culture. Many craftsmen have made attempts for its publicity. For instance, Zeng XP carved innovative olive-stone bookmarks, U disks, and other handicrafts, while Zhou HJ designed fashion accessories, such as olive-stone necklaces and earrings. These cultural and innovative products are favored by many young people.

\subsection{Inheriting the culture of olive-stone carving through online platforms}

In recent years, live broadcasts, short videos, WeChat official accounts, and other media platforms are 
playing increasingly important roles in the inheritance of intangible cultural heritage. Some inheritors and enthusiasts display their crafting process and works through online platforms, attracting the attention of a large number of young people. In this context, craftsmen of olive-stone carving in Guangzhou are also trying to exhibit their handicrafts and promote the culture of olive-stone carving online. Some well-known bloggers have attracted more than 40,000 fans on Tiktok and accumulated even 110,000 likes for their works. On Bilibili, a website popular among young people, a video about olive-stone carving in Guangzhou has been played nearly 1,000 times. In September 2021, the author participated in the recording of The Olive-stone Carving Story on Mid-Autumn, an olive-stone carving cultural work in Guangzhou. The video was posted on the WeChat official account and gained surging views. It was later recommended to mainstream cultural learning platforms, thus sharing the charm of this culture to more people and expanding its social influence.

\section{Conclusion}

Under the impact of modern industrial civilization, traditional handicrafts all over the world are facing severe survival crises and development dilemmas; some traditional handicrafts are even facing extinction. The issue of inheriting and developing traditional handicrafts in a contemporary society is being explored by all walks of life in China. The Chinese government has set an intangible cultural heritage list including traditional handicrafts and issued relevant policies to adopt a combination of hierarchical protection and classified protection for the listed items. All sectors of society have responded positively to protect, inherit, develop, and revitalize traditional handicrafts in their respective professional fields. Overall, the Chinese society has set off an upsurge in the study of handicraft inheritance.

As found from surveys, in the new era, the inheritance of olive-stone carving in Guangzhou is still facing many challenges and crises. Fortunately, the local government and craftsmen are not just sitting around but conforming to the trend of the times to actively seek solutions from the perspectives of raw materials, channels of inheritance, product development, and promotion, looking for a new way of protection and inheritance by protecting raw materials, actively looking for inheritors, embracing the market, cooperating with online platforms, etc. The inheritance of olive-stone carving in Guangzhou connects the past with the future. It will be a subject of continuous research to inherit the traditional handicrafts and culture of olive-stone carving in Guangzhou, allowing it to permeate modern life and the world of young people.

\section{Funding}

This research was supported by Guangdong Province Educational Science Planning Project - Research on the Construction and Application of Flipped Classroom Mode in the Teaching of Environmental Design Projects in Colleges and Universities (Project Number: 2020GXJK439).

\section{Disclosure statement}

The author declares that there is no conflict of interest.

\section{References}

[1] Hou ZF, 2021, The Analysis of Characteristics of Olive-stone Carving in Guangzhou. Dazhongwenyi, 2021(13): 57-58. 
[2] Peng XR, 2019, The Analysis of Raw Materials of Olive-stone Carving in Guangzhou. Identification and Appreciation to Cultural Relics, 2019(8): 74.

[3] Peng XR, 2017, The Research of Protection and Inheritance of Olive-stone Carving in Guangzhou (Zengcheng). Dazhongwenyi, 2017(03): 48. 